\title{
Pancreatic Intraepithelial Neoplasia-2
}

National Cancer Institute

\section{Source}

National Cancer Institute. Pancreatic Intraepithelial Neoplasia-2. NCI Thesaurus. Code C4846.

A pancreatic mucinous intraepithelial neoplasia characterized by the presence of papillary and less often flat architectural patterns. Moderate cytological atypia is present with some loss of nuclear polarity, nuclear crowding or hyperchromatism. 